\title{
ANALISA DAN IMPLEMENTASI ASSOCIATION RULE DENGAN ALGORITMA APRIORI DALAM PENERIMAAN DOSEN STUDI KASUS PADA (STKIP) YPM BANGKO
}

\author{
Deni Satria \\ STIH Merangin \\ email: kkdeni.saviola@gmail.com
}

\begin{abstract}
Dalam mengambil sebuah keputusan salah satu algoritma yang dapat digunakan adalah Algoritma FP-Growth. Dikarenakan Algoritma FP-Growth adalah Algoritma yang penyempurnaan dari Algoritma Apriori sehingga dengan menggunakan Algoritma FP-Growth kita akan mudah dalam mencari frequent itemse dan menentukan atau menemukan rule dari basis data yang besar. Dalam penelitian ini, menggunakan Algoritma FP-Growth yang bisa digunakan dalam mencari itemset dan menemukan aturan asosiasi atau rule sehingga akan membantu pimpinan dalam mengambil sebuah keputusan dari penerimaan dosen pada Sekolah Tinggi Keguruan Dan Ilmu Pendidikan.
\end{abstract}

Keywords: Data Mining, FP-growth, frequent itemset,rule.

\section{PENDAHULUAN}

Di masa sekarang ini perguruan tinggi negeri maupun swasta mengalami perkembangan yang sangat pesat. Beberapa aturan baru telah diterapkan untuk memajukan dunia pendidikan di Indonesia. Salah satu aturan yang diterapkan yaitu kualifikasi pendidikan dosen harus satu jenjang diatas Mahasiswa yang diajar.

Frequent Pattern Growth adalah salah satu alternatif algoritma yang dapat digunakan untuk menentukan himpunan data yang paling sering muncul (frequent itemset) dalam sebuah kumpulan data. Frequent pattern tree merupakan struktur penyimpanan data yang dimampatkan. Frequent pattern tree dibangun dengan memetakan setiap data transaksi ke dalam setiap lintasan tertentu dalam frequent pattern tree.

Algoritma FP-Growth merupakan pengembangan dari algoritma Apriori. Sehingga kekurangan dari algoritma
Apriori diperbaiki oleh algoritma $F P$ Growth ((Meilani D.B, Asadulloh M, 2015).

Dosen adalah pendidik profesional dan ilmuwan dengan tugas utama mentransformasikan,mengembangkan dan penyebarluaskan ilmu pengetahuan, teknologi, dan seni melalui pendidikan, penelitian, dan pengabdian kepada masyarakat (Peraturan Menteri Pendidikan dan kebudayaan no 84, 2013).

Salah satu kunci utama dalam menciptakan sumber daya manusia (SDM) yang profesional adalah terletak pada proses rekrutmen, seleksi, training dan development calon tenaga kerja. Profesional dosen merupakan bagian yang paling potensial dalam menentukan kualitas lulusan di suatu perguruan tinggi (Terttiaavini, Agustri. S, 2015)

Dalam penelitian ini, penulis memiliki beberapa tujuan yang ingin dicapai, tujuan tersebut yaitu : 
1. Memahami teori yang berkaitan dengan AssociationRule dengan algoritma FP-Growth.

2. Menganalisa indikator-indikator yang berhubungan dengan penerimaan dosen pada Sekolah Tinggi Keguruan dan Ilmu Pendidikan STKIP YPM Bangko.

3. Melakukan pengujian terhadap Analisa Kasus yang diteliti.

4. Mengimplementasikan hasil dari Algoritma FP-Growth dalam Software yang akan digunakan.

Selain itu tujuan penelitian ini juga diharapkan dapat memberikan manfaat bagi berbagai pihak yang nantinya. Adapun manfaat penelitian ini antara lain :

1. Memberikan suatu pengetahuan dalam penerimaan dosen yang berkompeten agar mendapatkan dosen yang mempunyai skill dan dapat ditempatkan sesuai dengan bidang keilmuannya.

2. Diharapkan dengan adanya hasil dari Peritungan Penunjang Keputusan ini dapat memberikan pemahaman yang jelas Bagaimana cara untuk mendapatkan dosen yang sesuai dengan kebutuhan dan memberikan dampak positif atau negatif dalam penerimaan dosen.

\section{METODE PENELITIAN}

Tujuan dari penulisan ini adalah membuat kerangka kerja secara keseluruhan tentang penggunaan Data Mining dan menentukan kelayakan dosen yang melamar pada Sekolah Tinggi Keguruan dan Ilmu Pendidikan (STKIP) YPM Bangko Menggunakan Association Rule dengan Algoritma FP-Growth sehingga memberikan pemahaman terhadap pembaca secara sistematik dan terstruktur.

\subsection{Kerangka Kerja}

Kerangka kerja ini merupakan langkah-langkah yang dilakukan dalam rangka penyelesaian masalah yang akan dibahas. Secara umum sistematika yang dimaksud terdapat beberapa langkah-langkah yang harus dilakukan dalam tesis ini seperti yang terlihat pada gambar 2.1 Berikut.

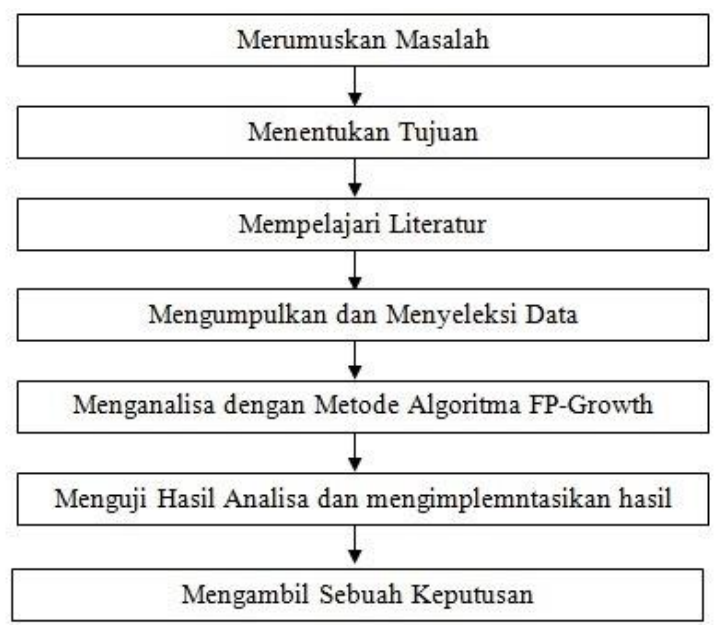

Gambar 2. 1 Kerangka kerja Penelitian

Dari Kerangka yang digambarkan pada gambar 3.1 dapat diuraikan pembahasan masing-masing kegiatan sebagai berikut, Yaitu :

a. Merumuskan Masalah Pada tahap ini dilakukan peninjauan ke sistem yang sedang berlangsung untuk mengamatik serta melakukan eksplorasi lebi dalam menggali Permasalahan yang ada. Tahap perumusan masakah merupakan langkah awal dari Penelitian ini. Karena tahap ini diperlukan untuk mengidentifikasi keingginan dari sistem yang tidak tercapai. 
b. Menentukan Tujuan

Berdasarkan perumusan masalah yang telah dibuat pada tahap sebelumnya, maka tahap penentuan tujuan berguna untuk memperjelas kerangka tentang apa saja yang akan menjadi sasaran dari penelitian ini. Pada tahap ini ditentukan tujuan dari penelitian ini adalah bagai mana menganalisa dan mengimplementasikan suatu sistem yang sedang berjalan agar mendapatkan kelayakan seorang dosen yang dapat deterima dengan ujian psikotes dan wawancara yang dilakukan.

c. Mempelajari Literatur

Studi pustaka dilakukan dengan tujuan untuk mengetahui metode apa yang akan digunakan untuk menyelesaikan permasalahan yang akan diteliti, serta mendapatkan dasar-dasar referensi yang kuat bagi peneliti dalam menerapkan suatu metode yang digunakannya.

d. Mengumpulkan dan menyeleksi Data.

Pada Tahap ini dilakukan pengumpulan data untuk lebih mengetahui mengenai sistem yang diteliti. Dari data yang dikumpulkan akan dapat diketahui mengenai sistem yang berjalan pada saat ini. Data-data yang diperlukan dalam penelitian ini adalah data calon dosen memenuhi syarat untuk menjadi dosen di Sekolah Tinggi Keguruan dan Ilmu Pendidikan (STKIP) YPM Bangko.

e. Menganalisa Dengan Metode Algoritma FP-Growth

Tahap analisa sistem bertujuan untuk mempelajari masalah dan kelemahan yang timbul dari penerimaan dosen. Permasalahan dan kelemahan tersebut akan diidentifikasi yang mana nantinya kan dirangkai dengan datadata lain sehingga dapat menjadi sebuah informasi yang mendukung dalam mengambil sebuah keputusan.

Analisa merupakan sebuah proses yang mana bertujuan untuk mempermudah pimpinan untuk mengambil sebuah keputusan, serta untuk mengrtahui kebutuhan yang diperlukan dalam penyaringa penerimaan dosen, sehingga pada akhirnya akan mendapatkan dosen yang benar-benar memenuhi semua kriteria yang dicari oleh Sekolah Tinggi Keguruan dan Ilmu Pendidikan (STKIP) YPM Bangko.

Dari hasil Analisa maka hendaknya dapat diimplementasikan dengan sebaik-baik nya sehingga pada saat penerimaan dosen pada Sekolah Tinggi Keguruan dan Ilmu Pendidikan (STKIP) YPM Bangko akan menerima dosen dengan kriteria atau kebutuhan yang dibutuhkan oleh Sekolah Tinggi Keguruan dan Ilmu Pendidikan (STKIP) YPM Bangko.

f. Menguji Hasil Dengan Software RAPID MINER

Setelah menganalisa selesai, maka pada tahap ini dilakukan penggujian terhadap Analisi tersebut sehingga hasil dari analisis dari pengujian model tahap implentasi dengan menggunakan aplikasi RAPID MINER sebagai aplikasiny Menggunakan metode agoritma FP-Growth jika dari hasil analisis tersebut dapat diimplentasikan dengan baik maka kebutuhan dan utnuk selanjutnya model yang dirancang ini dapat digunakan.

g. Menguji Hasil Implementasi

Pada tahap pengujian hasil ini akan diuji menggunakan sebuah software yang mana pada akhir nya nanti apakah data yang telah dialanisis dapat diuji kebenaran nya dengan sebuah software, sehingga apakah dari hasil analisis tersebut benar-benar dapat membantu seorang pimpinan untuk mengambil sebuah keputusan tentang perek rutan seorang dosen yang dibutuhkan oleh sebuah institus. Adapun mekanisme pengujian yang akan dilakukan adalah :

1. Pengujian manual dengan menggunakan rumus-rumus pada masing-masing itemset dan 
selanjutnya adalah dengan membentuk Association Rule

2. Pengujian dengan menggunakan aplikasi microsoft excel, Yaitu dengan mencocokkanhasil yang didapat dari rumus manual dan dimasukkan kedalam rumus formula dalam microsoft excel

3. Penggujian dengan menggunakan sebuah aplikasi yang dirancang untuk penggujian sebuah algoritma FP-Growth.

h. Menarik Kesimpulan

Pada tahap menarik kesimpulan ini akan mengetahui apakah hasil dari analisis dan implementasi ini bisa diterapkan untuk melakukan sebuah perekrutan dosen sesuai dengan yang dibutuhkan diharapkan. Serta untuk membandingkan hasil yang didapat pada tahap analisis dan implementasi yang dibuat secara manual.

\section{HASIL DAN PEMBAHASAN}

\subsection{Analisa Permasalahan}

Langkah pertama yang dilakukan penulis adalah menganalisa dan mengelompok data agar dapat mempermudah dalam menganalisa dan mengimplementasikan yang telah direncanakan sebelumnya sesuai dengan variable - variabel yang dibutuhkan.

Dalam tahapan menganalisa data dengan Algoritma FP-GROWTH penulis Maka dari itu dapat pula disebut pembentukan kombinasi satu item. Tahap selanjutnya dari item-item yang telah terseleksi dibentuk lah kombinasi dua item, maka terbentuk lah beberapa item data dengan kombinasi 2 item yang berbeda, dengan support yang ditentukan maka terseleksi lah beberapa data dua item, ini disebut pembentukan kombinasi dua item. Demikian seterusnya sampai kombinasi batas maksimal item dari data Penerimaan dosen.
Bagian ini menyajikan hasil penelitian. Hasil penelitian dapat dilengkapi dengan tabel, grafik (gambar), dan/atau bagan. Bagian pembahasan memaparkan hasil pengolahan data, menginterpretasikan penemuan secara logis, mengaitkan dengan sumber rujukan yang relevan.

\subsection{Persiapan Data}

Algoritma FP-GROWTH menentukan kandidat yang mungkin muncul dengan cara memperhatikan nilai support dan nilai confidence. Support adalah nilai kemunculan variabel atau persentase kombinasi sebuah item dalam database sedanglkan confidence adalah kuatnya hubungan antar item dalam aturan asosiasi.

Dalam penelitian ini penulis mengambil 20 sample pelamar untuk menjadi dosen di STKIP YPM Bangko dan kemudian 20 sample yang didapat adalah sample pelamar 2 tahun terakhir di STKIP YPM Bangko.

Tabel 3.1 Data Awal yang didapat dari STKIP YPM Bangko

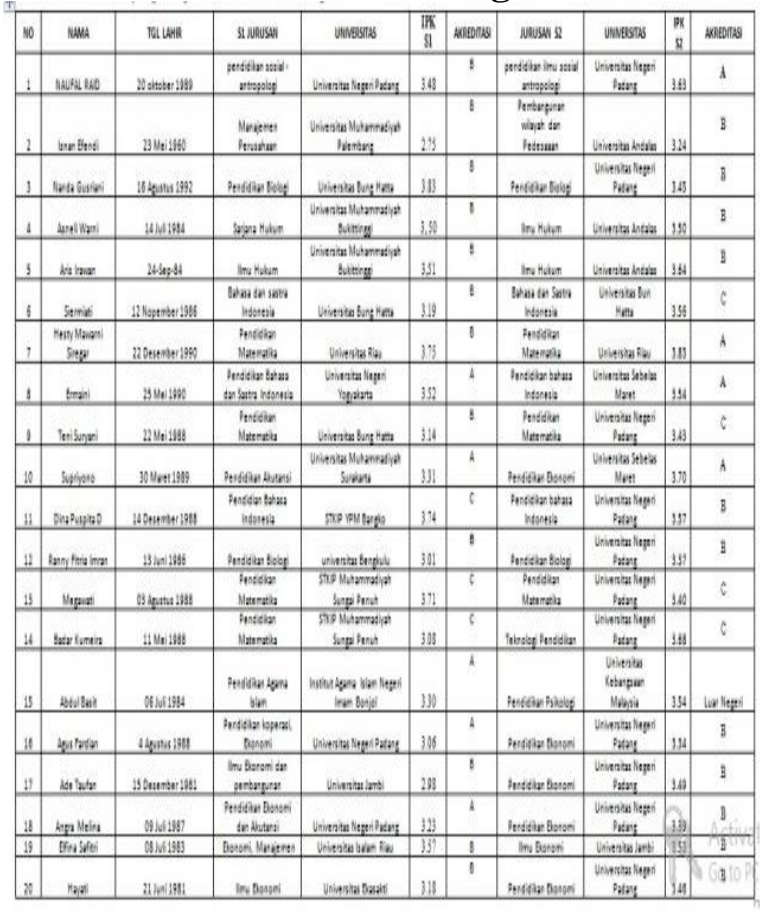

Setelah kita mendapatkan data dalam penerimaan dosen ini maka langkah selanjutnya yang harus kita lakukan adalah bagai mana mengelompokkan data, 
membuat variable-veriabel sehingga yang ada pada table 3.1, yang mana akan dikelompokkan menjadi 4 variabel yaitu : variable Umur, Variabel Linieritas pendidikan pelamar, variable Indeks prestasi komulatif dan variable akreditasi jurusan pelamar. Pada proses menentukan variable-variabel penerimaan dosen maka akan diberikan kode $\mathrm{P}$ yang mana artinya pelamar dan 1 adalah Nomor Urut Pelamar.

\section{Tabel 3.2 Variabel Umur Pelamar}

\begin{tabular}{|l|c|c|c|c|} 
Pelamar & Tahun Lahir & Tahun Sekarang & Umur & Nilai \\
\hline P1 & 1989 & 2016 & 27 & 1 \\
\hline P2 & 1960 & 2016 & 56 & 0 \\
\hline P3 & 1992 & 2016 & 24 & 1 \\
\hline P4 & 1984 & 2016 & 32 & 1 \\
\hline P5 & 1984 & 2016 & 32 & 1 \\
\hline P6 & 1986 & 2016 & 30 & 1 \\
\hline P7 & 1990 & 2016 & 26 & 1 \\
\hline P8 & 1990 & 2016 & 26 & 1 \\
\hline P9 & 1988 & 2016 & 28 & 1 \\
\hline P10 & 1989 & 2016 & 27 & 1 \\
\hline P11 & 1988 & 2016 & 28 & 1 \\
\hline P12 & 1986 & 2016 & 30 & 1 \\
\hline P13 & 1988 & 2016 & 28 & 1 \\
\hline P14 & 1988 & 2016 & 28 & 1 \\
\hline P15 & 1984 & 2016 & 32 & 1 \\
\hline P16 & 1988 & 2016 & 28 & 1 \\
\hline P17 & 1981 & 2016 & 35 & 1 \\
\hline P18 & 1987 & 2016 & 29 & 1 \\
\hline P19 & 1983 & 2016 & 33 & 1 \\
\hline P20 & 1981 & 2016 & 35 & 1 \\
\hline
\end{tabular}

Pada Variabel umur ini adalah pelamar yang mempunyai umur dibawah 35 tahun, setiap pelamar yang mempunyai umur dibawah 35 tahun akan diberikan kode 1 , sedangkan pelamar yang umur nya diatas 35 tahun akan diberikan kode 0

\section{Tabel 3.3 Variabel Linieritas Pendidikan}

\begin{tabular}{l|l|l|c|} 
Pelamar & \multicolumn{1}{|c|}{ Jurusan S1 } & \multicolumn{1}{|c}{ Jurusan S2 } & Kode \\
\hline P1 & pendidikan sosial - antropologi & $\begin{array}{l}\text { pendidikan ilmu sosial } \\
\text { antropologi }\end{array}$ & 1 \\
\hline P2 & Manajemen Perusahaan & $\begin{array}{l}\text { Pembangunan wilayah dan } \\
\text { Pedesaaan }\end{array}$ & 0 \\
\hline P3 & Pendidikan Biologi & Pendidikan Biologi & 1 \\
\hline P4 & Ilmu Hukum & Ilmu Hukum & 1 \\
\hline P5 & Ilmu Hukum & Ilmu Hukum & 1 \\
\hline P6 & Bahasa dan Sastra Indonesia & Bahasa dan Sastra Indonesia & 1 \\
\hline P7 & Pendidikan Matematika & Pendidikan Matematika & 1 \\
\hline P8 & Pendidikan Bahasa dan Sastra & Pendidikan bahasa Indonesia & 1 \\
\hline Indonesia & Pendidikan Matematika & Pendidikan Matematika & 1 \\
\hline P10 & Pendidikan Akutansi & Pendidikan Ekonomi & 1 \\
\hline P11 & Pendidian Bahasa Indonesia & Pendidikan bahasa Indonesia & 1 \\
\hline P12 & Pendidikan Biologi & Pendidikan Biologi & 1 \\
\hline P13 & Pendidikan Matematika & Pendidikan Matematika & 1 \\
\hline P14 & Pendidikan Matematika & Teknologi Pendidikan & 0 \\
\hline P15 & Pendidikan Agama Islam & Pendidikan Psikologi & 0 \\
\hline P16 & Pendidikan Ekonomi & Pendidikan Ekonomi & 1 \\
\hline P17 & Imu Ekonomi & Pendidikan Ekonomi & 0 \\
\hline P18 & Pendidikan Ekonomi & Pendidikan Ekonomi & 1 \\
\hline P19 & Ekonomi, Manajemen & Ilmu Ekonomi & 1 \\
\hline P20 & Ilmu Ekonomi & Pendidikan Ekonomi & 0 \\
\hline & & &
\end{tabular}

Pada Tabel ini dijelaskan apakah jenjang pendidikan yang ditempuh setiap pelamar yang mempunyai linierritas pada pendidikan kejenjang berikut nya, jika pendidikan awal yang diambi sesuai dengan jenjang pendidikan berikut nya maka akan diberikan kode 1, sedangkan pelamar yang jenjang pendikan awal tidak sesuai dengan pendidikan kejenjang berikutnya maka akan diberikan nilai 0

\section{Tabel 3.4 Variabel Indeks Prestasi Komulatif}

\begin{tabular}{|l|c|c|} 
Pelamar & IPK & Kode \\
\hline P1 & 3.63 & 1 \\
\hline P2 & 3.24 & 0 \\
\hline P3 & 3.45 & 1 \\
\hline P4 & 3.50 & 1 \\
\hline P5 & 3.64 & 1 \\
\hline P6 & 3.56 & 1 \\
\hline P7 & 3.83 & 1 \\
\hline P8 & 3.54 & 1 \\
\hline P9 & 3.43 & 1 \\
\hline P10 & 3.70 & 1 \\
\hline P11 & 3.57 & 1 \\
\hline P12 & 3.37 & 1 \\
\hline P13 & 3.40 & 1 \\
\hline P14 & 3.68 & 1 \\
\hline P15 & 3.54 & 1 \\
\hline P16 & 3.34 & 1 \\
\hline P17 & 3.49 & 1 \\
\hline P18 & 3.39 & 1 \\
\hline P19 & 3.53 & 1 \\
\hline P20 & 3.46 & 1 \\
\hline & & \\
\hline
\end{tabular}

Pada tabel ini Menjelaskan tentang Indeks Prestasi Komulatif Pelamar pada Variabel ini indeks prestasi komulatif bagi pelamar ditetapkan oleh pihak kampus STKIP YPM Bangko adalah 3.25, sehingga pelamar yang mempunyai indeks prestasi sama dengan atau lebih dari 3,25 akn kita beri kode 1 sedangkan yang indeks prestasi komulatifnya dibawah 3.25 akan kita beri kode 0 . 


\section{Tabel 3.5 Variabel Akreditasi Pelamar}

\begin{tabular}{|c|c|c|}
\hline PELAMAR & AKREDITASI & Kode \\
\hline P1 & A & $\mathbf{1}$ \\
\hline P2 & B & $\mathbf{1}$ \\
\hline P4 & B & $\mathbf{1}$ \\
\hline P5 & B & $\mathbf{1}$ \\
\hline P6 & C & 0 \\
\hline P7 & A & $\mathbf{1}$ \\
\hline P8 & A & $\mathbf{1}$ \\
\hline P9 & C & o \\
\hline P10 & A & $\mathbf{1}$ \\
\hline P11 & B & $\mathbf{1}$ \\
\hline P12 & B & $\mathbf{1}$ \\
\hline P13 & C & 0 \\
\hline P14 & C & 0 \\
\hline P15 & LUAR NEGERI & 0 \\
\hline P16 & B & $\mathbf{1}$ \\
\hline P17 & B & $\mathbf{1}$ \\
\hline P18 & B & $\mathbf{1}$ \\
\hline P19 & B & $\mathbf{1}$ \\
\hline P20 & B & $\mathbf{1}$ \\
\hline & & \\
\hline
\end{tabular}

Pada tabel ini Menjelaskan tentang akreditasi program studi pelamar. Pada tabel akreditasi ini akreditasi yang bernilai A dan B maka akan diberikan kode 1 sedangkan akreditasi yang bernilai $\mathrm{C}$ akan diberikan kode 0 dan pada variable Akreditasi Pelamar ini akreditasi kampus yang diambil adalah akreditasi terakhir pada jenjang pendidikan pelamar.

\section{Tahap Perhitungan Algoritma FP-Growth}

Setelah semua data dan variabel yang dibutuhkan telah di kelompokkan maka langkah selanjutnya adalah menggabungkan semua data dan variabel yang telah dibuat:

Tabel 3.7 Data Rekapitulasi Pelamar

\section{Dosen Di STKIP YPM Bangko}

\begin{tabular}{|l|l|l|l|l|}
\hline Pelamar & \multicolumn{1}{|c|}{ Umur } & \multicolumn{1}{|c|}{ Jurusan } & \multicolumn{1}{|c|}{ Ip } & \multicolumn{1}{c|}{ Akreditasi } \\
\hline P1 & True & True & True & True \\
\hline P2 & False & False & False & True \\
\hline P3 & True & True & True & True \\
\hline P4 & True & True & True & True \\
\hline P5 & True & True & True & True \\
\hline P6 & True & True & True & False \\
\hline P7 & True & True & True & True \\
\hline P8 & True & True & True & True \\
\hline P9 & True & True & True & False \\
\hline P10 & True & True & True & True \\
\hline P11 & True & True & True & True \\
\hline P12 & True & True & True & True \\
\hline P13 & True & True & True & False \\
\hline P14 & True & False & True & False \\
\hline P15 & True & False & True & False \\
\hline P16 & True & True & True & True \\
\hline P17 & True & False & True & True \\
\hline P18 & True & True & True & True \\
\hline P19 & True & True & True & True \\
\hline P20 & True & False & True & True \\
\hline
\end{tabular}

Pada Tabel ini Tentang data pelamar pada STKIP YPM Bangko, pada pada table dijelaskan bahwa jika "umur = True" maka "umur pelamar $<35$ " dan jika " Jurusan pelamar $=$ True" Maka " jurusan pelamar adalah Linier" dan Jika “ Ip Pelamar $=$ True" Maka "IP pelamar $>3.25$ " dan "Jika Akreditasi Pelamar $=$ True " maka " Akreditasi Pelamar =A, B " Berikutnya data yang didapatkan dari tabel ini dikonversikan menjadi tabel berikut ini

Tabel 3.8 Tabel Konversi dari Tabel data pelamar.

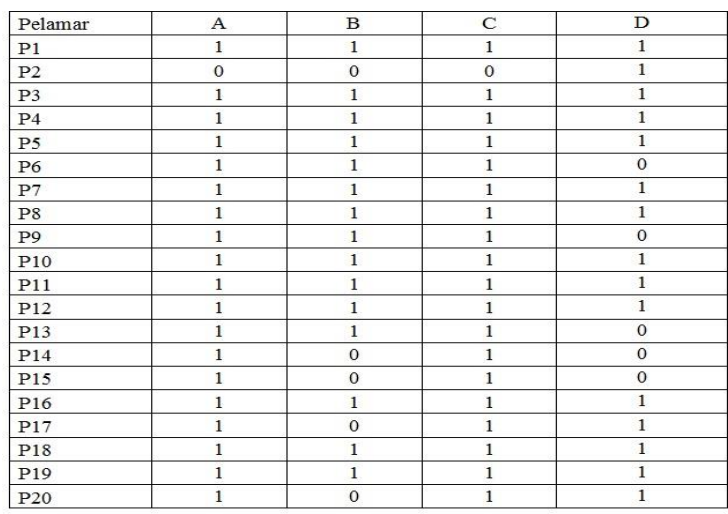

Maka dari tabel diatas bahwasanya angka satu dapat disebut mewakili data pelamar yang memenuhi syarat, sedangkan angka 0 mewakili persyaratan pelamar yang tidak memenuhi syarat.

Kemudian data yang ada pada tebel 4.7 (Syarat yang bernilai 1) akan kita ambil dan kita masukkan kedalam tabel 4.8 yaitu tabel kriteria kemunculan pelamar sedangkan pelamar yang tidak memenuhi syarat tidak kita masukkan kedalam tabel 4.8.

Tabel 3.9 Data Item Kriteria Kemunculan Pelamar

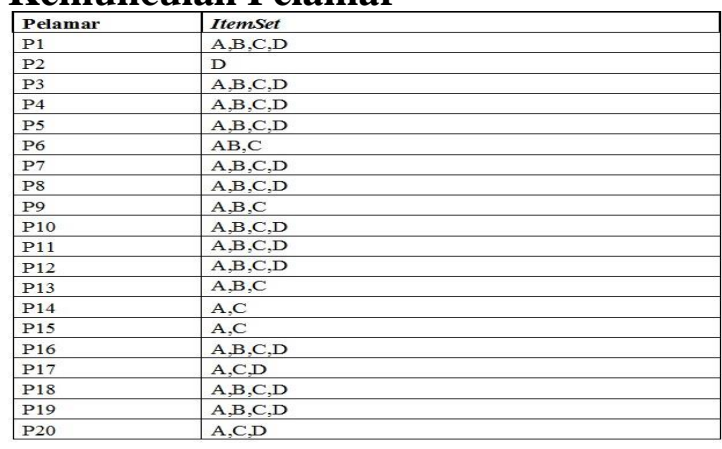


Tabel 3.10 Tabel Frekuensi

\section{Kemunculan Item Diurutkan}

Berdasarkan Frekuensi Tertinggi.

\begin{tabular}{|c|l|}
\hline Variabel Pelamar & Jumlah Itemset \\
\hline A & 19 \\
\hline C & 19 \\
\hline D & 15 \\
\hline B & 15 \\
\hline
\end{tabular}

Setelah dilakukan Pengurutan didapat item yang memiliki frekuensi di atas support count $\geq 15$ adalah $\mathrm{A}, \mathrm{B}, \mathrm{C}, \mathrm{D}$. Ke-4 (empat) item ini yang akan dimasukkan kedalam FP-Tree, selebihnya dapat dibuang karena tidak terlalu berpengaruh, Sehingga menghasilkan tabel 3.11

\begin{tabular}{|l|l|}
\hline Pelamar & Jumlah ItemSet \\
\hline P1 & A,C,D,B \\
\hline P2 & D \\
\hline P3 & A,C,D,B \\
\hline P4 & A,C,D,B \\
\hline P5 & A,C,D,B \\
\hline P6 & A,C,B \\
\hline P7 & A,C,D,B \\
\hline P8 & A,C,D,B \\
\hline P9 & A,C,B \\
\hline P10 & A,C,D,B \\
\hline P11 & A,C,D,B \\
\hline P12 & A,C,D,B \\
\hline P13 & A,C,B \\
\hline P14 & A,C \\
\hline P15 & A,C \\
\hline P16 & A,C,D,B \\
\hline P17 & A,C,D \\
\hline P18 & A,C,D,B \\
\hline P19 & A,C,D,B \\
\hline P20 & A,C,D \\
\hline
\end{tabular}

\subsection{Tahap Pembangunan FP-Tree}

Pada tahap pembangunan FP-Tree ini Langkah selanjutnya yaitu tahap pembuatan FP-Tree yang mana pada tahap ini kita akan melakukan pembuatan FPtree dengan menggunakan data pelamar untuk menjadi dosen pada STKIP YPM Bangko yang mana semua data yang ada telah diurutkan berdasarkan kategori yang sering muncul, Dengan perolehan Frequent Items setelah dipangkas dan diurutkan, maka akan dibangun FP-Tree

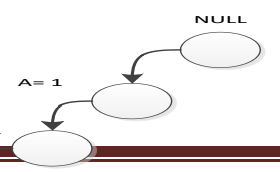

\section{Gambar 3.1 Hasil Pembentukan FP - Tree Setelah Pembacaan P1(A,C,D,B)}

Pemindaian pertama, yaitu pembacaan pelamar (P1) $\{A, C, D, B\}$ akan membuat simpul A, C, D, dan B sehingga terbentuk lintasan Syarat Pelamar Null $\rightarrow \mathrm{A} \rightarrow \mathrm{C} \rightarrow \mathrm{D} \rightarrow \mathrm{B}$. Support count dari setiap simpul bernilai awal 1 (satu).

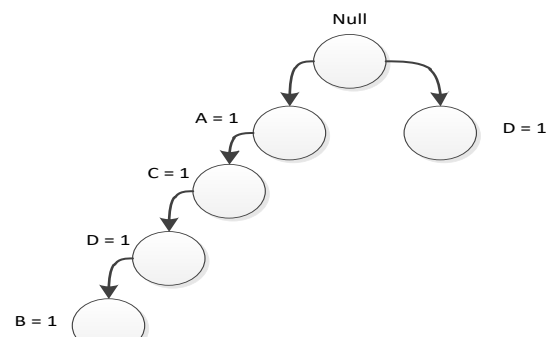

\section{Gambar 3.2 Hasil Pembentukan FP Tree Setelah Pembacaan P2 (D)}

Pemindaian kedua, yaitu pembacaan pelamar (P2) $\{D\}$ akan membuat simpul Baru yaitu simpul D sehingga terbentuk lintasan Syarat Pelamar Null $\rightarrow$ D. Support count dari setiap simpul bernilai awal 1 (Satu).

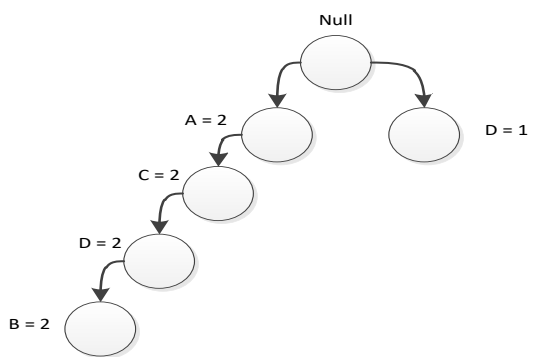

Gambar 3.3 Hasil Pembentukan FPTree Setelah Pembacaan P3 (A, C, D, B)

Pemindaian ketiga, yaitu pembacaan pelamar $(\mathrm{P} 3)\{A, C, D, B\}$ akan menambah nilai simpul $\mathrm{A}, \mathrm{C}, \mathrm{D}$, dan $\mathrm{B}$ sehingga terbentuk lintasan Syarat Pelamar 
Null $\rightarrow \mathrm{A} \rightarrow \mathrm{C} \rightarrow \mathrm{D} \rightarrow \mathrm{B}$. Support count dari setiap simpul bernilai awal 2(Dua).

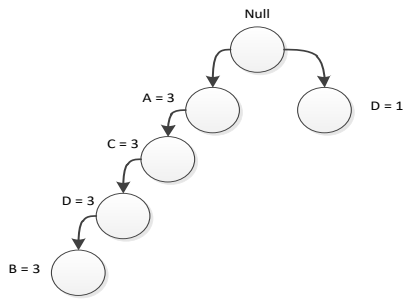

\section{Gambar 3.4 Hasil Pembentukan FP-} Tree Setelah Pembacaan P4 (A, C, D, B)

Pemindaian keempat, yaitu pembacaan pelamar (P5) $\{A, C, D, B\}$ akan Menambah Nilai simpul A, C, D, dan B sehingga terbentuk lintasan Syarat Pelamar Null $\rightarrow \mathrm{A} \rightarrow \mathrm{C} \rightarrow \mathrm{D} \rightarrow \mathrm{B}$. Support count dari setiap simpul bernilai awal 3 (Empat).

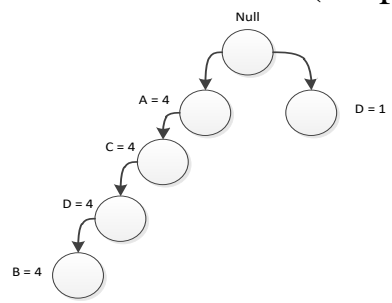

Gambar 3.5 Hasil Pembentukan FPTree Setelah Pembacaan P5 (A, C, D,B)

Pemindaian kelima, yaitu pembacaan pelamar (P5) $\{A, C, D, B\}$ akan membuat simpul A, C, D, B sehingga terbentuk lintasan Syarat Pelamar Null $\rightarrow \mathrm{A} \rightarrow \mathrm{C} \rightarrow \mathrm{D} \rightarrow \mathrm{B}$. Support count dari setiap simpul bernilai awal 4 (Empat).

Maka pemindaian data akan terus terjadi sampai pada pembacaan pelamar (P20), sehingga pada saat data pelamar (P20) maka akan mendapatkan hasil pembentukan FP-Tree akan seperti ini :

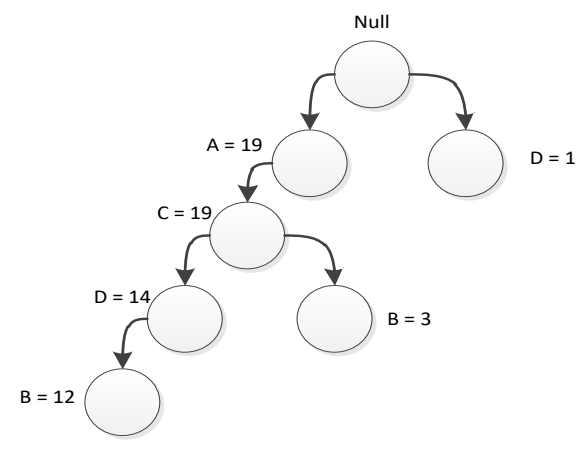

Gambar 3.6 Hasil Pembentukan FPTree Setelah Pembacaan P20 (A,C,D)

Pemindaian Dua Puluh, yaitu pembacaan pelamar (P17) $\{A, C, D\}$ akan membuat simpul A, C, D sehingga terbentuk lintasan Syarat Pelamar Null $\rightarrow \mathrm{A} \rightarrow \mathrm{C} \rightarrow \mathrm{D}$. Support count pada simpul $\mathrm{A} \rightarrow \mathrm{C}$ akan bernilai 19 ( Sebelas) sedangkan D Bernilai 14 (Empat belas).

\subsection{Tahap Pencarian Frequent Itemset}

Dalam menemukan frequent itemset maka diperlukan upapohon (pohon yang akarnya adalah keturuan dari akar pohon induknya) dengan lintasan yang memiliki support count terkecil, yaitu

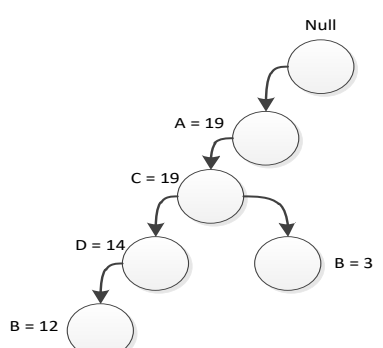

Nilai yang memiliki lintasan B. Proses pembentukannya dapat dilihat pada gambar berikut :

\section{Gambar 3.7 Lintasan yang memiliki noda B}

Kemudian kita akan mencari nilai lintasan yang memiliki noda D maka proses pembentukan nodanya dapat dilihat pada gambar 4.19 di bawah ini :

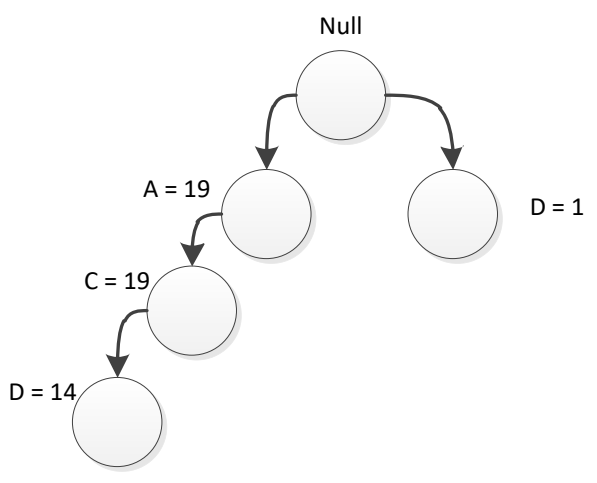

Gambar 3.8 Lintasan yang memiliki noda D 
Kemudian kita akan mencari nilai lintasan yang memiliki noda $\mathrm{C}$ maka proses pembentukan nodanya dapat dilihat pada gambar 4.20 di bawah ini :

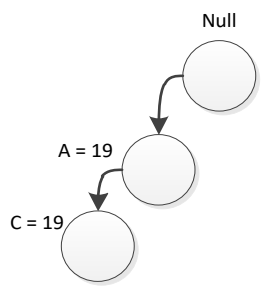

\section{Gambar 3.9 Lintasan yang memiliki noda $\mathbf{C}$}

Kemudian kita akan mencari nilai lintasan A maka proses pembentukan nodanya dapat dilihat pada gambar $4.21 \mathrm{di}$ bawah ini :

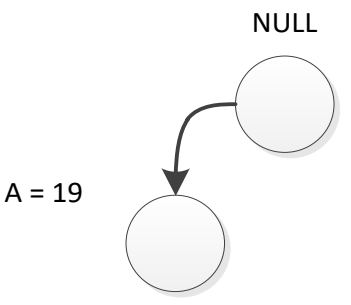

\section{Gambar 4.10 Lintasan yang memiliki noda $A$}

Pada Gambar 4.21 Semua Variabel A dihapus. Lintasan diambil acuan adalah Fp-tree lengkap yang ada pada gambar 4.21 .

\subsection{Rule Asosiasi Algoritma Fp-Growth pertama Untuk menentukan Rule} Asosiasi Algoritma Fp-Growth adalah menemukan semua frequent itemset yang berakhiran A, C, D, B maka kita harus mengecek apakah support count dari A,C, $\mathrm{D}, \mathrm{B}$ telah memenuhi minimum support count $\geq 3$.

Dari pembangkitan FP-tree yang telah dilakukan maka didapatkan hasil Conditional Pattern Base Seperti ditampilkan dalam tabel.

\begin{tabular}{|c|l|}
\hline Suffix & \multicolumn{1}{|c|}{ Conditional Pattern Base } \\
\hline A & $\{(A): 19\}$ \\
\hline C & $\{(C): 19,(A, C): 19\}$ \\
\hline$D$ & $\{(D): 15,(A, C, D): 14,(A, C): 19,(C, D): 14\}$ \\
\hline
\end{tabular}

Dari pembangkitan conditional FPTree telah dilakukan sebelumnya maka, didapatkan hasil conditional FP-Tree dan hasil Coditional Tree yang dapat dilihat

\begin{tabular}{|c|l|l|}
\hline psidfa tableodibiawtahBini & Conditional FP-Tree \\
\hline A & $\{(\mathrm{A}): 19\}$ & $(\mathrm{A} ; 19)$ \\
\hline $\mathrm{C}$ & $\{(\mathrm{C}): 19,(\mathrm{~A}, \mathrm{C}): 19\}$ & $\{(\mathrm{A}: 19)(\mathrm{C}: 19)\}$ \\
\hline $\mathrm{D}$ & $\begin{array}{l}\{(\mathrm{D}): 15,(\mathrm{~A}, \mathrm{C}, \mathrm{D}): 14, \\
(\mathrm{A}, \mathrm{C}): 19,(\mathrm{C}, \mathrm{D}): 14\}\end{array}$ & $\{(\mathrm{D}: 15),(\mathrm{C}: 14))(\mathrm{A}: 14)\}$ \\
\hline B & $\begin{array}{l}\{(\mathrm{B}): 15,(\mathrm{~A}, \mathrm{C}, \mathrm{D}, \mathrm{B}): 12, \\
(\mathrm{A}, \mathrm{C}, \mathrm{B}): 3,(\mathrm{~A}, \mathrm{C}, \mathrm{D}): 14, \\
(\mathrm{C}, \mathrm{D}, \mathrm{B}): 12,(\mathrm{D}, \mathrm{B}): 12, \\
(\mathrm{C}, \mathrm{B}): 3\}\end{array}$ & $\left\{\begin{array}{l}(\mathrm{B}: 15),(\mathrm{D}: 12),(\mathrm{C}: 15),(\mathrm{A}: 15)\} \\
\hline\end{array}\right.$ \\
\hline
\end{tabular}

\subsection{Frequen Item Set}

Setelah didapatkan Conditional FPtree maka Langkah Selanjutnya adalah menentukan Frequen Item Set.

\begin{tabular}{|c|c|l|r|}
\hline No & Frequen Itemset & \multicolumn{2}{|l|}{ Support } \\
\hline 1 & $\mathrm{C}, \mathrm{A}$ & $19 / 20$ & $95 \%$ \\
\hline 2 & $\mathrm{C}, \mathrm{D}$ & $14 / 20$ & $70 \%$ \\
\hline 3 & $\mathrm{C}, \mathrm{B}$ & $15 / 20$ & $75 \%$ \\
\hline 4 & $\mathrm{~A}, \mathrm{D}$ & $14 / 20$ & $70 \%$ \\
\hline 5 & $\mathrm{~A}, \mathrm{~B}$ & $15 / 20$ & $75 \%$ \\
\hline 6 & $\mathrm{D}, \mathrm{B}$ & $15 / 20$ & $75 \%$ \\
\hline 7 & $\mathrm{C}, \mathrm{A}, \mathrm{D}$ & $14 / 20$ & $70 \%$ \\
\hline 8 & $\mathrm{C}, \mathrm{A}, \mathrm{B}$ & $15 / 20$ & $75 \%$ \\
\hline 9 & $\mathrm{C}, \mathrm{D}, \mathrm{B}$ & $15 / 20$ & $75 \%$ \\
\hline 10 & $\mathrm{~A}, \mathrm{D}, \mathrm{B}$ & $12 / 20$ & $60 \%$ \\
\hline 11 & $\mathrm{C}, \mathrm{A}, \mathrm{D}, \mathrm{B}$ & $15 / 20$ & $75 \%$ \\
\hline
\end{tabular}

Maka selanjutnya adalah menentukan rule dengan cara menghitung nilai support dan confidence-nya. maka itemset yang dihitung minimal berisi dua item.

Dari ke-11 subsets yang dihasilkan selanjutnya akan dihitung nilai support dan confidence-nya. Hanya kombinasi yang lebih besar sama dengan minimum confidence yang akan diambil atau strong association rule nya saja. Berdasarkan frequent itemset di atas maka confidence yang dihasilkan adalah :

Agar tingkat akurasinya tinggi, Berikut adalah nilai confidence yang melewati minimum confidence $\geq 86 \%$

\begin{tabular}{|c|c|c|c|c|}
\hline \multirow{2}{*}{ No } & \multicolumn{3}{|c|}{ Confidance } & Persentase \\
\hline 1 & D & C & $14 / 15$ & $93 \%$ \\
\hline 2 & D & A & $14 / 15$ & $93 \%$ \\
\hline 3 & D & C, A & $14 / 15$ & $93 \%$ \\
\hline 4 & C & A & $19 / 19$ & $100 \%$ \\
\hline 5 & A & C & $19 / 19$ & $100 \%$ \\
\hline 6 & B & C & $15 / 15$ & $100 \%$ \\
\hline 7 & B & A & $15 / 15$ & $100 \%$ \\
\hline 8 & C, D & A & $14 / 14$ & $100 \%$ \\
\hline 9 & A, D & C & $14 / 14$ & $100 \%$ \\
\hline Bishis & JTEKS BIS & C, A & $15 / 15$ & $100 \%$ \\
\hline 11 & C, B & A & $15 / 15$ & $100 \%$ \\
\hline 12 & A, B & C & $15 / 15$ & $100 \%$ \\
\hline 13 & D, B & C & $14 / 12$ & $100 \%$ \\
\hline 14 & D, B & A & $14 / 12$ & $100 \%$ \\
\hline 15 & D, B & C, A & $14 / 12$ & $100 \%$ \\
\hline 16 & C, D, B & A & $15 / 15$ & $100 \%$ \\
\hline 17 & A D B & C & $15 / 15$ & $100 \%$ \\
\hline
\end{tabular}


Setelah diketahui nilai dari Support diatas maka kita akan melakukan perhitungan nilai Confidence setiap association rule yang dilalui maka diperolehlah hasil secara ke seluruhan yang terlihat dalam table.

\begin{tabular}{|c|c|c|c|c|}
\hline No & Jika & Maka & Support & Confidance \\
\hline 1 & D & C & $70 \%$ & $93 \%$ \\
\hline 2 & D & A & $70 \%$ & $93 \%$ \\
\hline 3 & D & C, A & $70 \%$ & $93 \%$ \\
\hline 4 & C & A & $95 \%$ & $100 \%$ \\
\hline 5 & A & C & $95 \%$ & $100 \%$ \\
\hline 6 & B & C & $75 \%$ & $100 \%$ \\
\hline 7 & B & A & $75 \%$ & $100 \%$ \\
\hline 8 & C, D & A & $70 \%$ & $100 \%$ \\
\hline 9 & A, D & C & $70 \%$ & $100 \%$ \\
\hline 10 & B & C, A & $75 \%$ & $100 \%$ \\
\hline 11 & C, B & A & $75 \%$ & $100 \%$ \\
\hline 12 & A, B & C & $75 \%$ & $100 \%$ \\
\hline 13 & D,B & C & $60 \%$ & $100 \%$ \\
\hline 14 & D,B & A & $60 \%$ & $100 \%$ \\
\hline 15 & D,B & C,A & $60 \%$ & $100 \%$ \\
\hline 16 & C,D,B & C & $60 \%$ & $100 \%$ \\
\hline 17 & A,D,B & C & $60 \%$ & $100 \%$ \\
\hline
\end{tabular}

Rule 1 : Jika dilakukan seleksi penerimaan calon dosen dengan Akreditasi dan IPK pelamar dengan Nilai kepercayaan kualifikasi penerimaan dosen sebesar 93\% dan didukung oleh nilai pendukung $70 \%$ maka pelamar tersebut dapat direkomendasikan menjadi dosen.

Rule 2 : Jika dilakukan seleksi penerimaan calon dosen dengan Akreditasi dan Umur pelamar dengan Nilai kepercayaan kualifikasi penerimaan dosen sebesar 93\% dan didukung oleh nilai pendukung $70 \%$ maka pelamar tersebut dapat direkomendasikan menjadi dosen.

Rule 3 : Jika dilakukan seleksi penerimaan calon dosen dengan Akreditasi dan IPK,Umur pelamar dengan Nilai kepercayaan kualifikasi penerimaan dosen sebesar $93 \%$ dan didukung oleh nilai pendukung $70 \%$ maka pelamar tersebut dapat direkomendasikan menjadi dosen.

Rule 4 : Jika dilakukan seleksi penerimaan calon dosen dengan IPK dan Umur pelamar dengan Nilai kepercayaan kualifikasi penerimaan dosen sebesar $100 \%$ dan nilai pendukung $75 \%$ maka pelamar tersebut dapat direkomendasikan menjadi dosen.

Rule 5 : Jika dilakukan seleksi penerimaan calon dosen dengan Umur dan IPK pelamar dengan Nilai kepercayaan kualifikasi penerimaan dosen sebesar $100 \%$ dan nilai pendukung $95 \%$ maka pelamar tersebut dapat direkomendasikan menjadi dosen.

Rule 6 : Jika dilakukan seleksi penerimaan calon dosen dengan Jurusan dan IPK pelamar dengan Nilai kepercayaan kualifikasi penerimaan dosen sebesar $100 \%$ dan nilai pendukung $75 \%$ maka pelamar tersebut dapat direkomendasikan menjadi dosen.

Rule 7 : Jika dilakukan seleksi penerimaan calon dosen dengan Jurusan dan IPK pelamar dengan Nilai kepercayaan kualifikasi penerimaan dosen sebesar $100 \%$ dan nilai pendukung $75 \%$ maka pelamar tersebut dapat direkomendasikan menjadi dosen.

Rule 8 : Jika dilakukan seleksi penerimaan calon dosen dengan IPK, Akreditasi dan Umur pelamar dengan Nilai kepercayaan kualifikasi penerimaan dosen sebesar $100 \%$ dan nilai pendukung $70 \%$ maka pelamar tersebut dapat direkomendasikan menjadi dosen. 
Rule 9 : Jika dilakukan seleksi penerimaan calon dosen dengan Umur, Akreditasi, dan IPK pelamar dengan Nilai kepercayaan kualifikasi penerimaan dosen sebesar $100 \%$ dan nilai pendukung $70 \%$ maka pelamar tersebut dapat direkomendasikan menjadi dosen.

Rule 10 : Jika dilakukan seleksi penerimaan calon dosen dengan Jurusan dan IPK, Umur pelamar dengan Nilai kepercayaan kualifikasi penerimaan dosen sebesar $100 \%$ dan nilai pendukung $75 \%$ maka pelamar tersebut dapat direkomendasikan menjadi dosen.

Rule 11: Jika dilakukan seleksi penerimaan calon dosen dengan IPK, Jurusan dan Umur pelamar dengan Nilai kepercayaan kualifikasi penerimaan dosen sebesar $100 \%$ dan nilai pendukung $75 \%$ maka pelamar tersebut dapat direkomendasikan menjadi dosen.

Rule 12 : Jika dilakukan seleksi penerimaan calon dosen dengan Umur, Jurusan dan IPK pelamar dengan Nilai kepercayaan kualifikasi penerimaan dosen sebesar $100 \%$ dan nilai pendukung $75 \%$ maka pelamar tersebut dapat direkomendasikan menjadi dosen.

Rule 13 : Jika dilakukan seleksi penerimaan calon dosen dengan Akreditasi, Jurusan dan IPK pelamar dengan Nilai kepercayaan kualifikasi penerimaan dosen sebesar $100 \%$ dan nilai pendukung $60 \%$ maka pelamar tersebut dapat direkomendasikan menjadi dosen.

Rule 14 : Jika dilakukan seleksi penerimaan calon dosen dengan Akreditasi, Jurusan dan Umur pelamar dengan Nilai kepercayaan kualifikasi penerimaan dosen sebesar $100 \%$ dan nilai pendukung $60 \%$ maka pelamar tersebut dapat direkomendasikan menjadi dosen.
Rule 15 : Jika dilakukan seleksi penerimaan calon dosen dengan Akreditasi, Jurusan dan IPK, Umur pelamar dengan Nilai kepercayaan kualifikasi penerimaan dosen sebesar $100 \%$ dan nilai pendukung $60 \%$ maka pelamar tersebut dapat direkomendasikan menjadi dosen.

Rule 16 : Jika dilakukan seleksi penerimaan calon dosen dengan IPK, Akreditasi, Jurusan dan Umur pelamar dengan Nilai kepercayaan kualifikasi penerimaan dosen sebesar $100 \%$ dan nilai pendukung $60 \%$ maka pelamar tersebut dapat direkomendasikan menjadi dosen.

Rule 17: Jika dilakukan seleksi penerimaan calon dosen dengan Umur, Akreditasi, Jurusan dan IPK pelamar dengan Nilai kepercayaan kualifikasi penerimaan dosen sebesar $100 \%$ dan nilai pendukung $60 \%$ maka pelamar tersebut dapat direkomendasikan menjadi dosen

\section{KESIMPULAN DAN SARAN}

\subsection{Kesimpulan}

Dari uraian pada bab-bab yang sudah dibahas sebelumnya dapat ditarik kesimpulan :

1. Dengan menggunakan Algoritma FPGrowth dalam melakukan perekrutan dosen akan sanggat membantu untuk mendapatkan dosen yang sesuai dengan kebutuhan dan dengan menggunakan Algoritma FP-growth maka seorang pimpinan akan mendapatkan sebuah informasi yang sangat efisien dalam mengambil sebuah keputusan yang tepat.

2. Dengan menggunakan Al-goritma FpGrowth dan didukung dengan aplikasi Rapid Miner 7.3.00 maka seorang pimpinan akan dapat mengambil sebuah keputusan sesuai dengan kebutuhan di STKIP YPM Bangko

\subsection{Saran}

Implementasi Algoritma FP-Growth dalam membuat rule atau aturan untuk 
pengambilan keputusan bagi seorang pimpinan. Berikut adalah saran yang dapat diperhatikan untuk masa yang akan datang.

1. Sebaik nya digunakan dua Algoritma agar data yang dihasilkan dalam membuat sebuah keputusan lebih akurat.

2. Agar mendapatkan hasil rule yang lebih akurat sebaiknya ditambahkan variabel-variabel yang belum ada sehingga data frequent Item Set dan rule yang dihasilkan oleh Aplikasi Rapid miner akan lebih akurat.

\section{DAFTAR PUSTAKA}

Melani DB, Asadulloh. (2015). Data Mining Untuk Menggali Pola Mahasiswa Baru Menggunakan Metode Frequent Pattern Growth (Studi Kasus : Institut Teknologi Adhi Tama Surabaya)

Aggarwal.S, (2013) Beberapa algoritma yang termasuk dalam Aturan Asosiasi adalah seperti AIS Algorithm, FP-Growth Algorithm, DHP Algorithm, dan Partition Algorithm.

Tampubolon.K, Saragih.H, Reza.B, (2013). Implementasi Data Mining Algoritma Apriori pada sistem persediaan alat-alat kesehatan: ISSN 2339-210x

Terttiaavini, Agustri. S, (2015). Sistem Informasi E-Recruitment dosen pada perguruan tinggi swasta. ISSN Online : $\mathbf{3 4 7 7 : 3 7 8 6}$

Ikmah, (2016). sistem pendukung keputusan seleksi penerimaan dosen menggunakan metode topsis. ISSN 2302-3805

Jailani, Defit.S, Nurcahyo,G.W, (2015). Penerapan Algoritma C4.5 Pada NUPTK untuk Menentukan Pola ertifikasi Guru dengan menggunakan metode klasifikasi decesion tree (Studi kasus pada dinas pendidikan pemuda dan olah raga kabupaten rokan hulu, Vol.1/No.1/2015 : 69-83 .

Kurniawati.A, (2014). Data mining juga sering disebut sebagai Knowledge Discovery in Databases (KDD). KDD terdiri dari tiga proses utama Hardjana, Agus M. (2003). Komunikasi Intrapersonal \& Komunikasi Interpersonal. Yogyakarta: Penerbit Kanisius.

Han dan Kamber, (2006). Knowladge discovery sebagai sebuah proses yang digambarkan pada gambar 2.1, dan terdiri atas runtunan iterative dari langkah-langkah yang ada .

Ardani N.R, Fitrina N, (2016). Sistem

Rekomendasi Pemesanan Sparepart Dengan Algoritma FpGrowth (Studi Kasus Pt. Rosalia Surakarta). ISSN : 2302-3805.

Yusuf W,Y., Pratikto,F,R, Gerry T., (2006). Penerapan Data Mining Dalam Penentuan Aturan Asosiasi Antar Jenis Item . ISSN: 19075022.

Ikhwan.A, Nofriansyah.D, Sriani., (2015). Penerapan Data Mining dengan Algoritma Fp-Growth untuk Mendukung Strategi Promosi Pendidikan ( Studi Kasus Kampus STMIK Triguna Dharma). ISSN : 1978-6603. 